\title{
Conductivity of Cellulose Acetate Membranes from Pandan Duri Leaves (Pandanus tectorius) for Li-ion Battery
}

\author{
Endang W. Laksono, Marfuatun and Demas Aji \\ Department of Chemistry, Faculty of Mathematics and Natural Sciences, Yogyakarta State University, Yogyakarta 55281, Indonesia
}

\begin{abstract}
The purpose of this research is to know the influence of lithium chloride composition on membrane conductivity. Cellulose was extracted from pandan duri leaves (P. tectorius) by dilute alkaline and bleaching with $0.5 \% \mathrm{NaOCl}$ followed by synthesis of cellulose acetate using acetic anhydride as acetylating agent, acetic acid as solvent and sulfuric acid as catalyst. The membranes were prepared by casting polymer solution method and the composition of $\mathrm{CA} / \mathrm{LiCl}$ were $60 / 40,65 / 35,70 / 30,75 / 25,80 / 20$ and 100/0. Structural analysis was carried out by FTIR and X-ray diffraction. The conductivity was measured using Elkahfi 100. The highest conductivity of cellulose acetate membrane was $2.20 \times 10^{-4} \mathrm{~S} \mathrm{~cm}^{-1}$ that measured at room temperature for $65 / 35$ composition
\end{abstract}

\section{Introduction}

Nowadays, many people in this century are using portable electronic devices such as smartphone, smartwatch, digital camera, laptop and tablet to support their daily activities. Many of them are powered by lithium ion (Li-ion) battery due to its high energy density, lack of memory effect, long cycle life, high charge and discharge rate capabilities [1, 2]. Although it has many advantages, Li-ion battery has safety problem due to the using of liquid electrolyte that flammable and combustible, replacement of liquid electrolytes with polymer electrolytes is the best solution to the safety problem of li-ion battery [3].

Cellulose acetate (CA) membrane is the most common polymer electrolyte used, easily synthesized from cellulose of natural fibre [4]. The chemical method to obtain cellulose acetate is from esterification reaction of cellulose using acetic anhydride as an acetylating agent, acetic acid as a solvent and catalyst [5]. Polymer electrolytes like cellulose acetate has low conductivity, less than $10^{-6} \mathrm{~S} \mathrm{~cm}^{-1}[6,7]$. To enhance the conductivity of cellulose acetate, we can add 'salt' such as lithium chloride. The 'salt' is promising to increase the conductivity up to $10^{-3} \mathrm{~S} \mathrm{~cm}^{-1}$ due to the existence of lithium ion in the membrane [8].

In Indonesia, there are a lot of natural fibre plant. One of the natural fibre plant is Pandan duri. Pandan duri (Pandanus tectorius) is a plant from Pandanaceae family, which productively grow in this land. It called pandan duri because it has spiny margins on its leaves and 'duri' is refer to spine. Many people use the leaves as material for hand craft such as weaving (hat, bag, and mat) [9]. Pandan duri's leaves also has a potential to be develop as a raw material for cellulose acetate. According to Rasha
M. Sheltami and her co-workers [10], pandan duri leaves contain a large amount of cellulose. Approximately $37.3 \%$ cellulose from wet pandan duri leaves and $81.6 \%$ after bleached [10]. The aim of this work is to know the influence of lithium chloride composition on membrane conductivity.

\section{Experimental}

\subsection{Materials}

Pandan duri leaves gathered in Bantul (Yogyakarta, Indonesia) were used in this research. The reagents and chemicals using in this research were standard analytical grades such as acetic acid, acetic anhydride, sodium hydroxide, lithium chloride, acetone, ethanol, hydrochloric acid and other chemicals. All chemicals were purchased from Chemix Laboratory and used without further purification.

\subsection{Preparation of cellulose acetate membrane}

First, cut the leaves into small pieces, removed the unused pieces (midribs and spiny margins), dried under the sun and ground. Next, the dry leaves were placed in stagnant water for three days. Then the leaves were boiled for about $20 \mathrm{~min}$. The leaves were dried under the sun and ground again. Cellulose was isolated by soaking $\mathrm{NaOH}$ at room temperature and $80^{\circ} \mathrm{C}$ for $2 \mathrm{~h}$. Next, bleached using $0.5 \% \mathrm{NaOCl}$. Then washed with distilled water for several times. Cellulose acetate was obtained by dissolved cellulose from pandan duri leaves in acetic acid and acetic anhydride with ratio of acetic acid to acetic anhydride was 70:27 (v/v). The ratio of cellulose to liquor 
was 5:112 $(\mathrm{g} / \mathrm{mL})$. Sulfuric acid was used as catalyst. Cellulose acetate membrane was prepared by dissolving cellulose acetate and $\mathrm{LiCl}$ in acetic acid with ratio 1:20 $(\mathrm{g} / \mathrm{mL})$. The composition of $\mathrm{CA} / \mathrm{LiCl}$ were $100 / 0$ (blank), $80 / 20,75 / 25,70 / 30,65 / 35$, and 60/40. Then, a mixture of $\mathrm{CA}$ and $\mathrm{LiCl}$ was casting on Teflon ${ }^{\mathrm{TM}}$ medium and dried at room temperature.

\subsection{Determination of the degree of substitution (DS)}

A mixture composed by $0.1 \mathrm{~g}$ cellulose from pandan duri leaves and $4 \mathrm{~mL}$ of $75 \%$ ethanol was heated at $60^{\circ} \mathrm{C}$ for $30 \mathrm{~min}$. Then, $5 \mathrm{~mL}$ of $0.5 \mathrm{~N} \mathrm{NaOH}$ was added to the mixture, which was heated at $60^{\circ} \mathrm{C}$ for $15 \mathrm{~min}$. Next, the mixture was left to stand at room temperature for three days. After this time, the sample was titrated with $0.5 \mathrm{~N}$ $\mathrm{HCl}$ using phenolphthalein as the indicator and left to stand for $24 \mathrm{~h}$. An excess of $\mathrm{HCl}$ was then back titrated with $0.5 \mathrm{~N} \mathrm{NaOH}$. A blank has same procedure determination for a control system of sample. The percentage of acetyl was calculated from Eq. (1):

$$
\operatorname{Acetyl}(\%)=\left[\left(V_{d}-V_{c}\right) N_{\mathrm{NaOH}}+\left(V_{a}-V_{b}\right) N_{\mathrm{HCl}}\right] x \frac{4.305}{w}
$$

where, $V a=\mathrm{NaOH}$ volume required for titration of the sample; $V b=\mathrm{NaOH}$ volume required for titration of the blank; $V c=\mathrm{HCl}$ volume required for titration of the sample; $V d=\mathrm{HCl}$ volume required for titration of the blank; $w=$ weight of the sample. The degree of substitution (DS) of the sample was calculated from Eq. (2):

$$
D S=\frac{3.86 x \operatorname{Acetyl}(\%)}{102.40-\operatorname{Acetyl}(\%)}
$$

\subsection{Determination of the viscosity-average molecular weight $\left(\bar{M}_{\mathrm{v}}\right)$}

Determination of molecular weight of cellulose acetate did by viscometry. To measure the viscosity-average molecular weight ( $\bar{M} \mathbf{v})$, add five solutions with different concentration $(1,2,3,4$ and $5 \mathrm{mg}$ ) of cellulose acetate and dissolved in $10 \mathrm{ml}$ acetone. The efflux time for each solution was measured by Ostwald viscometer. $\bar{M}_{\mathrm{v}}$ was determined with Mark-Houwink-Sakurada Eq. (3):

$$
[\eta]=k \bar{M}_{\mathrm{v}}{ }^{a}
$$

where $[\eta]=$ intrinsic viscosity; $k$ and $a$ are constants related to the polymer, solvent and temperature.

\subsection{Characterization}

FTIR spectra was performed on a Nicolet Avatar 360 using the $\mathrm{KBr}$ pellets method in the range $4000-400 \mathrm{~cm}^{-1}$ for pandan duri leaves, cellulose, and cellulose acetate powder from synthesis. The possible changes in the functional groups of cellulose acetate membranes at different composition of $\mathrm{LiCl}$ were investigated using Perkin Elmer, Frontier FT-IR Spectrometer Universal ATR sampling accessory in the range $4000-500 \mathrm{~cm}^{-1}$ with scanning resolution of $16 \mathrm{~cm}^{-1}$. The conductivity of CA membranes were obtained using Elkahfi 100 in the range $0.05-9 \mathrm{~V}$ with maximum current $0.0035 \mathrm{~A}$. The thickness of membranes were obtained using NSK micrometer. The conductivity of CA membrane was calculated by:

$$
\sigma=\frac{\ln 2}{\pi t R}
$$

where, $\sigma=$ the membrane conductivity; $\mathrm{t}=$ the thickness of membrane; $\mathrm{R}=$ the membrane resistance. The crystallinity of CA membrane was obtained using a Rigaku Miniflex 600 Benchtop X-ray diffractometer equipped with $\mathrm{CuK}_{\alpha}$ radiation at $40 \mathrm{kV}$ and $15 \mathrm{~mA}$ in the range of $2 \theta=2-90^{\circ}$. Crystallinity $\left(X_{\mathrm{c}}\right)$ of CA membrane was calculated by [11]:

$$
X_{\mathrm{c}}(\%)=\frac{A_{\mathrm{c}}}{A_{\mathrm{a}}+A_{\mathrm{c}}} \times 100 \%
$$

where, $A a=$ area under amorphous peaks and $A c=$ area under crystalline peaks.

\section{Results and discussion}

In this work cellulose acetate was obtained by cellulose acetylation from pandan duri leaves using acetic anhydride as acetylating agent. Each step was characterized by FTIR to ensure the possible changes in functional groups of each product. Figure 1 shows the FTIR spectra obtained for (a) pandan duri leaves, (b) cellulose from pandan duri leaves and (c) cellulose acetate from pandan duri leaves. Figure 1a shows the band at $1734.15 \mathrm{~cm}^{-1}$ is attributed to $\mathrm{C}=\mathrm{O}$ stretching of ester groups of hemicellulose and was no longer exist after the alkali treatment (Figure 1b) due to the cleavage of all ester groups of hemicellulose by alkali treatment $[12,13]$. The absorbance peaks in the region $1511.91 \mathrm{~cm}^{-}$ ${ }^{1}$ and 1253.28 reflect the stretching of the $\mathrm{C}=\mathrm{C}$ aromatic and C-O-C (aryl-alkyl-ether) of lignin, respectively. These peaks slightly disappeared after pandan duri leaves dissolved in $\mathrm{NaOCl}$, which indicated the absence of lignin [14].

Figure $1 \mathrm{~b}$ shows the disappearance of the absorbance peaks in the region $1734.15 \mathrm{~cm}^{-1}, 1511.91 \mathrm{~cm}^{-1}$ and $1253.28 \mathrm{~cm}^{-1}$ suggest the successful of cellulose extraction from pandan duri leaves. The spectrum (c) in Figure 1 showing the presence of important cellulose acetate band at $1754.37 \mathrm{~cm}^{-1}(\mathrm{C}=\mathrm{O}$ ester $), 1375.10 \mathrm{~cm}^{-1}$ $\left(\mathrm{C}-\mathrm{H}\right.$ bond in $\left.-\mathrm{OCOCH}_{3}\right)$ and $1236.39 \mathrm{~cm}^{-1}(\mathrm{C}-\mathrm{O}-\mathrm{C}$ of ester group of pure cellulose acetate) $[15,16]$. In addition, the successful of acetylation process is shown by the absence of $\mathrm{C}=\mathrm{O}$ bond (symmetric and asymmetric) in the region $1825-1760 \mathrm{~cm}^{-1}$ and $1700 \mathrm{~cm}^{-1}$ as indicated that the cellulose acetate is free of the unreacted acids (acetic anhydride and acetic acid) [17]. The calculated degree of 
substitution (DS) of cellulose acetate was obtained a value of 2.76 .

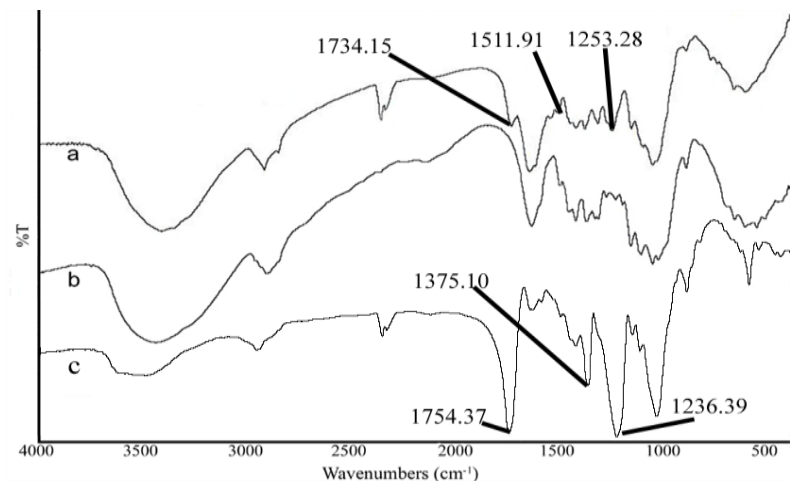

Figure 1. FTIR spectra of (a) pandan duri leaves, (b) cellulose of pandan duri leaves, and (c) cellulose acetate of pandan duri leaves.

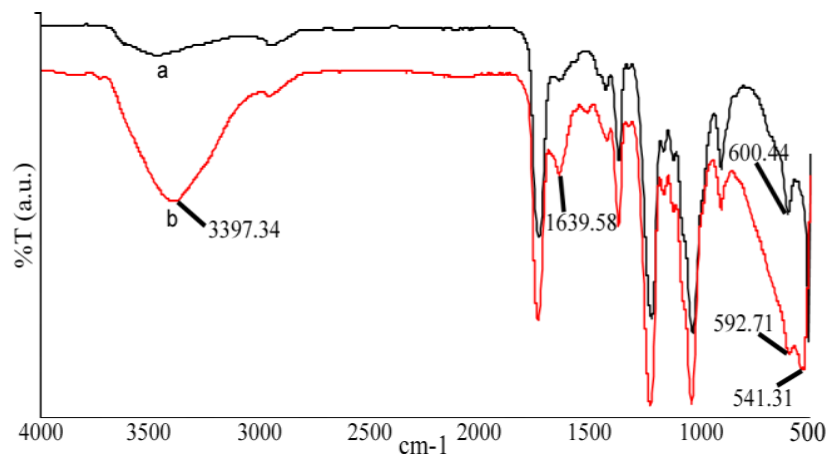

Figure 2. ATR-FTIR spectra of (a) Pure CA and (b) 65/35 $\mathrm{CA} / \mathrm{LiCl}$.

Table 1. Variation of conductivity of CA membranes under different salt concentrations.

\begin{tabular}{|c|c|}
\hline $\mathbf{C A} / \mathbf{L i C l}$ & Conductivity $\left.\mathbf{( S ~ c m}^{-\mathbf{1}}\right)$ \\
\hline $100 / 0$ & $1.54 \times 10^{-6}$ \\
\hline $80 / 20$ & $2.52 \times 10^{-3}$ \\
\hline $75 / 25$ & $3.78 \times 10^{-3}$ \\
\hline $70 / 30$ & $1.10 \times 10^{-2}$ \\
\hline $65 / 35$ & $2.95 \times 10^{-2}$ \\
\hline $60 / 40$ & $1.65 \times 10^{-2}$ \\
\hline
\end{tabular}

Table 1 shows the conductivity of cellulose acetate under different composition of $\mathrm{LiCl}$ with the thickness of membranes ranging from 0.001 to $0.035 \mathrm{~cm}$. The calculated conductivity of pure cellulose acetate was obtained a value of $1.54 \times 10^{-6} \mathrm{~S} \mathrm{~cm}^{-1}$ and the maximum conductivity value $2.95 \times 10^{-2} \mathrm{~S} \mathrm{~cm}^{-1}$ was obtained at room temperature for $65 / 35$ composition. The conductivity of cellulose acetate increase as $\mathrm{LiCl}$ concentration increase and decrease in $60 / 40 \mathrm{CA} / \mathrm{LiCl}$ composition. The conductivity of CA membrane increase due to the number of free ions $\left(\mathrm{Li}^{+}\right)$and decrease due to lithium ion association in cellulose acetate membrane.

Figure 2 shows the ATR-FTIR spectrum of pure cellulose acetate and $65 / 35 \mathrm{CA} / \mathrm{LiCl}$ composition. It can be seen that the absorbance of hydroxyl functional group at $3397.34 \mathrm{~cm}^{-1}$ of $65 / 35 \mathrm{CA} / \mathrm{LiCl}$ composition is higher than pure cellulose acetate and peak at $1639.58 \mathrm{~cm}^{-1}$ (Figure 2b) as indicated $\mathrm{HOH}$ hydration due to the presence of lithium chloride in cellulose acetate membrane. In addition, the absorbance peaks at 541.31 and $592.71 \mathrm{~cm}^{-1}$ suggest the existence of lithium in $65 / 35$ $\mathrm{CA} / \mathrm{LiCl}$ composition that enhance the conductivity of its membrane [18]. The XRD pattern of $65 / 35 \mathrm{CA} / \mathrm{LiCl}$ shows in Figure 3, was obtained $2 \theta$ value around $17.25^{\circ}$ and $23.02^{\circ}$. The low diffraction intensity indicate that the membrane was amorphous with the degree of crystallinity about $23.5 \%$.

The addition of salt like lithium chloride in cellulose acetate membrane was decrease the crystallinity of cellulose acetate membrane due to the structural modification associated with cellulose acetate membrane. It was contribute to the increasing in the conductivity due to the increase of free volume of its membrane and the ions can freely move [19].

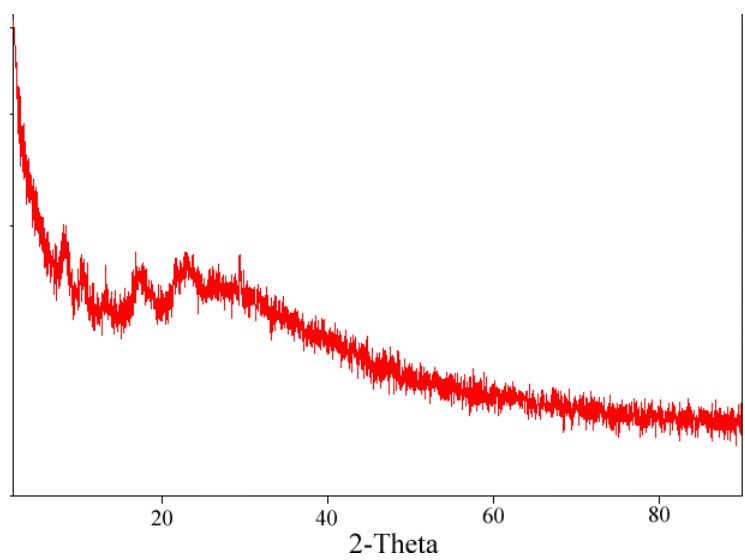

Figure 3. XRD pattern of $65 / 35 \mathrm{CA} / \mathrm{LiCl}$.

For the used solvent system, acetone, the intrinsic viscosity was obtained a value of $119.72 \mathrm{~mL} / \mathrm{g}$ and the Mark-Houwink-Sakurada constants are $K=0.133$ and $a=$ 0.616 [20]. The viscosity-average value molecular weight of cellulose acetate was $62,512 \mathrm{~g} \mathrm{~mol}^{-1}$.

\section{Conclusions}

Cellulose acetate can be obtained by cellulose acetylation from pandan duri leaves. The highest conductivity of cellulose acetate membrane was obtained for $65 / 35$ $\mathrm{CA} / \mathrm{LiCl}$ composition with a value of $2.95 \times 10^{-2} \mathrm{~S} \mathrm{~cm}^{-1}$. For the future work, the optimization of acetylation and addition of polymer like PEG or PVA are needed to increase the conductivity and mechanical properties of membrane.

\section{Acknowledgments}

This work was supported by DIPA UNY grant.

\section{References}

1. M. Rikukawa, K. Sanui, Prog. Poym. Sci., 25, $1463-$ 1502 (2000)

2. M. Lowe, S. Takuoka, T. Trigg, G. Gareffi, Lithiumion Batteries for Electric Vehicles: The U.S. Value Chain (CGGC, NC, 2010) 
3. J. S. Liu, W. S. Li, X. X. Zuo, S. Q. Liu, Z. Li, Journal of Power Source, 226, 101-106 (2013)

4. D. Alves Cerqueira, G. Rodrigues Filho, C. da Silva Meireles, Carbohydrate Polymers, 69, 578-582 (2007)

5. J. Cai, P. Fei, Z. Y. Xiong, Y. J. Shi, K. Yan, H. G. Xiong, Carbohydrate Polymers, 92, 11-18 (2013)

6. Parameswara Rao Chinnam, Hanjun Zhang, Stephanie L. Wunder, Electrochimica Acta, 170, 191-201 (2015)

7. M. Selvakumar, D. Krishna Bhat, Journal of Applied Polymer Science, 110, 594-602 (2008)

8. N. A. Razuki, A. W. Aziz, N. S. A. Satar, Noor Haida Mohd Kaus, Int. J. Electroactive Mater, 3, 3845 (2015)

9. W. Giesen, S. Wulffraat, M. Zieren, L. Scholten, Mangrove Guide Book for Southeast Asia (FAO and Wetlands International, The Netherlands, 2006)

10. R. M. Sheltami, I. Abdullah, I. Ahmad, A. Dufresne, H. Kargarzadeh, Carbohydrate Polymers, 88, 772779 (2012)

11. S. Gaidukov, I. Danielenko, G. Gaidukova, International Journal of Polymer Science, 2015, 1-8 (2015)
12. A. Alemdar, M. Sain, Bioresource Technology, 99, 1664-1671 (2008)

13. X. F. Sun, F. Xu, R. C. Sun, P. Fowler, M. S. Baird, Carbohydrate Research, 340, 97-106 (2005)

14. B. Xiao, X. F. Sun, Run Chang Sun, Polymer Degradation and Stability, 74, 307-319 (2001)

15. A. M. Das, A. A. Ali, M. P. Hazarika, Carbohydrate Polymers, 112, 342-349 (2014)

16. C. N. Saikia, F. Ali, T. Goswami, Anil C. Ghosh, Industrial Crops and Products, 4, 233-239 (1995)

17. X. F. Sun, R. C. Sun, J. X Sun, Bioresource Technology, 95, 343-350 (2004)

18. Jean-Joseph Max, Camille Chapados, J. Chem. Phys., 115, 2664 (2001)

19. A. Ahmad, M. Y. A. Rahman, S. P. Low, H. Hmazah, ISRN Materials Science, 2011, 1-7 (2011)

20. K. Kamide, T. Terakawa, Y. Miyazaki, Polymer Journal, 11, 285-289 (1979) 